\title{
Analysing the Impacts of Individual Factors on Decision Making and Strengthening Positive Attitudes on Vaccination
}

\author{
Sead Karakas ${ }^{1,2, ~ *, ~ M a t e j a ~ P a k l a r c i c ~}{ }^{2}$, Ermina Kukic ${ }^{2}$, Jasna Zukic ${ }^{3}$ \\ ${ }^{1}$ Faculty of Medicine, Univesity of Zenica, Zenica, Bosnia and Herzegovina \\ ${ }^{2}$ Institute for Public Health of the Central Bosnia Canton, Travnik, Bosnia and Herzegovina \\ ${ }^{3}$ Clinical Center of the University of Sarajevo, Sarajevo, Bosnia and Herzegovina
}

Email address:

tr.zavod@bih.net.ba (S. Karakas)

${ }^{*}$ Corresponding author

\section{To cite this article:}

Sead Karakas, Mateja Paklarcic, Ermina Kukic, Jasna Zukic. Analysing the Impacts of Individual Factors on Decision Making and Strengthening Positive Attitudes on Vaccination. American Journal of Pediatrics. Vol. 5, No. 3, 2019, pp. 116-124. doi: 10.11648/j.ajp.20190503.17

Received: June 17, 2019; Accepted: July 17, 2019; Published: August 5, 2019

\begin{abstract}
Aims and objectives: This paperwork aims to analyse the knowledge and attitudes on immunisation, subjective perceptions of the risks and decision theory of vaccination amongst the specific female population living in the Federation of Bosnia and Herzegovina. Purpose: The purpose of the research is to point out the significance of parents' decisions and strengthening of positive attitudes on vaccination. Material and methods: The research was conducted during 2018. Females from different parts of the Federation were asked questions. There were 4000 respondents of different ages ranging from 20 to 50 years old females (approximately 1\% of the target population). The respondents were classified according to their place of living (urban/rural), and also being a parent or not. The questionnaire was answered by 2504 respondents being parents with a certain experience with immunisation of their children, but also 1496 future parents who expressed their attitude towards immunisation. For this research, a special questionnaire was used, comprising 18 questions classified into 4 different groups. Results: Most of the respondents $(71.2 \%)$ who already have children claim they vaccinated their children completely whereas $2.0 \%$ respondents from urban areas and $1.3 \%$ from rural areas explicitly refuse to vaccinate their children. The rest of the respondents $(25.4 \%)$ claim they partially vaccinated their children or they are not familiar with the vaccination status of their children. Our research shows that parents are mostly informed about vaccinations and immunisation by some medical workers - paediatricians (36.6\%). This research also suggests that respondents are showing a great level of reluctance and scepticism towards some medical workers and that only $40.6 \%$ of respondents unconditionally trust their doctor. Additionally, the results show that considering the safety of vaccines there are significant differences amongst urban and rural population. In urban areas, $18.8 \%$ of respondents claim that they completely trust vaccines and in rural areas there are $36.2 \%$ of respondents trusting them. Conclusion: We may conclude that personal experience, medical system efficiency, trusting medical professionals, vaccine safety and communication in public health community are very important to make decisions on vaccinating children
\end{abstract}

Keywords: Accepting Vaccines, Safety, Hesitation, Immunisation

\section{Introduction}

Immunisation is an exceptionally powerful intervention for public health, because of its high affordability, safety and efficiency [1]. Only a few medical interventions have such longlasting positive impact, considering relatively small costs of immunisation. However, opposite to most medicaments, vaccines are usually given to healthy young people for the prevention and special emphasis goes to the safety of vaccines [2].

Although, accepting vaccines is generally on a very high level, the fear of getting them has dramatically increased in the last couple of years in many countries. In some 
communities, this fear led to significantly high rate of vaccine reluctance which is considered to have been related to some diseases and deaths that could have been prevented by a certain vaccine, and to big costs for health system and society in general [3].

First anti-vaccination campaigns began in Europe, as a respond to public measures determined by the law binding smallpox vaccination in the second half of the 19th century [4]. The controversy of pertussis vaccine which began in 1970 's in Great Britain is often considered to be the start of anti-vaccination campaign. The debate started in Great Britain, after Great Ormond St Hospital report in London had claimed that 36 children suffered from severe neurological consequences after DTaP immunisation. This report had drawn a considerable media coverage and it all became the matter of public concern. Until 1977, immunisation coverage with children, in Great Britain, decreased from $77 \%$ to $33 \%$. Three major pertussis epidemics spread with more than 100.000 cases and 36 children who died [5].

The modern campaign against vaccination again started in England in 1998, after Wakefield and authors had published that MMR vaccine had been related to autism and a variety of other diseases, which later on proved to be unfounded [6-7].

Less frequent diseases and activists fighting against vaccination drew public's attention to fear from unproven side effects, while some dangers of rare diseases, including risk of death, were neglected. Besides this, fast spreading of disinformation, including false information and misinformation on the Internet, makes it difficult for those who are trying to find some reliable information to distinguish scientific facts from unfounded claims. Successful or unsuccessful immunisation is related to the factors such as knowledge, attitude and practice of parents and patients [8].

This paperwork aims to analyse the knowledge and attitudes on immunisation, subjective perceptions of the risks and decision theory of vaccination amongst the specific female population living in the Federation of Bosnia and Herzegovina.

The purpose of the research is to point out the significance of parents' decisions and strengthening of positive attitudes on vaccination.

\section{Material and Methods}

\section{i. Area of research}

The research was conducted in the Federation of Bosnia and Herzegovina with the total area of $26.110 \mathrm{~km}^{2}$ and the population of 2.219 .220 (2013.), including 356.948 children (0-14 years old) and 473.938 women $(20-50$ years old $)$ as a target group of this research.

\section{ii. Subjects}

The research was being conducted during 2018. Females from different parts of the Federation were asked questions. There were 4000 respondents in 6 groups of different ages ranging from 20 to 50 years old females (approximately $1 \%$ of the target population). The respondents were classified according to their place of living (urban/rural), and also being a parent or not. The criterion for classifying urban area is such an area of 30.000 inhabitants. The questionnaire was answered by 2504 respondents being parents with a certain experience with immunisation of their children, but also 1496 future parents who expressed their attitude towards immunisation. This research was being conducted outside the medical institutions in order to avoid biases.

\section{iii. The Questionnaire}

For this research, a special questionnaire was used, comprising 18 questions classified into 4 different groups. The first part was made of some general data such as age, education and degree, marital status and parenting. The second part of this questionnaire was made of questions referring to vaccination knowledge, previous practice, illness preventions and vaccination benefits awareness. The third part referred to vaccine safety trust and its efficacy while the fourth part was made of questions referring to the impact from the environment and the media on the vaccine choice. The questions were open (structured) and closed (unstructured), including dichotomous questions (yes/no), nominal scale (more answers), the Likert scale (eg. uncertain, partially certain, mostly certain, very certain, absolutely certain), as well as some filter questions (eg. if answer is yes then respondents are asked more detailed follow-up questions). The questionnaire was distributed amongst respondents after it had been explained to them what the purpose had been and how to answer the questions. The female respondents had been assured that all the information they provided in this survey would be confidential and they had been asked to be completely honest while fulfilling the questionnaire.

\section{iv. Statistical analysis}

The data entry began at the same time as they were being collected. The research data were validated, verified and entered in MS Excel 2013. Incomplete and inconsistent data were discarded and not included into final analysis. Eventually, the data gathered from 4000 respondents were used for the analysis. The analysis was done by the SPSS v.17 software. The results are shown as absolute values (n) and percentages $(\%)$. The comparison between groups of categorical and binary data were calculated by chi-square test, and $\mathrm{P}<0,05$ values were considered to be statistically significant.

\section{v. Ethics}

This research has been approved by the Ethics Committee of our Institute for Public Health of the Central Bosnia Canton. All the participants gave verbal consent to take part in this research.

\section{Results}

There were 4000 respondents who participated in this research. The questionnaire was answered by 2504 respondents being parents with a certain experience with immunisation of their children, but also 1496 future parents who expressed their attitude towards immunisation when they get children (Table 1). 
Table 1. Respondents according to their age and parenting.

\begin{tabular}{llll}
\hline \multirow{2}{*}{ Age } & Having children & Not having children & Total \\
\cline { 2 - 4 } & $\mathbf{N}(\mathbf{\%})$ & $\mathbf{N} \mathbf{( \% )}$ & $\mathbf{N}(\mathbf{\% )}$ \\
\hline $20-24$ & $427(17.1 \%)$ & $327(21.9 \%)$ & $754(18.8 \%)$ \\
$25-29$ & $461(18.4 \%)$ & $351(23.4 \%)$ & $812(20.3 \%)$ \\
$30-34$ & $486(19.4 \%)$ & $373(24.9 \%)$ & $859(21.5 \%)$ \\
$35-39$ & $440(17.5 \%)$ & $205(13.7 \%)$ & $645(16.1 \%)$ \\
$40-44$ & $434(17.3 \%)$ & $137(9.2 \%)$ & $571(14.3 \%)$ \\
$45-49$ & $256(10.3 \%)$ & $103(6.9 \%)$ & $359(9.0 \%)$ \\
Total & 2504 & 1496 & $4000(100 \%)$ \\
\hline
\end{tabular}

Female respondents belong to the population of $20-50$ years old women, classified into 6 groups of different ages, with the average age $\mathrm{M}=32.68$ years old.

Most of the respondents, $35.7 \%$, have a high school degree, $23.7 \%$ have a university degree and $18.7 \%$ have a college degree. $12.5 \%$ of respondents have a primary school degree whereas only $9.4 \%$ of respondents are MAs or PhDs. It is significant to point out the difference between respondents according to their degree (Test result of chi- square $=860.9$, df (4), $p<0,01)$. The specimen shows $66.2 \%$ of employed and $33.8 \%$ of unemployed respondents.

According to the place of living, 2056 (51.4\%) respondents come from urban and 1944 (48.6\%) come from rural area. There is no significant difference between respondents according to their place of living ( chi-square $3.13, \mathrm{p}=0.076)$.

Respondents, who have children, have mostly decided to vaccinate them (Table 2).

Table 2. Have you vaccinated your children?

\begin{tabular}{|c|c|c|c|c|c|c|c|c|c|}
\hline \multirow{3}{*}{ Age } & \multicolumn{2}{|l|}{ Fully } & \multicolumn{2}{|l|}{ Partially } & \multicolumn{2}{|c|}{ Refuse to vaccinate } & \multicolumn{2}{|c|}{ Don't know } & \multirow{2}{*}{ Total } \\
\hline & $\mathbf{U}$ & $\mathbf{R}$ & $\mathbf{U}$ & $\mathbf{R}$ & $\mathbf{U}$ & $\mathbf{R}$ & $\mathbf{U}$ & $\mathbf{R}$ & \\
\hline & $\mathbf{N}(\%)$ & N (\%) & $\mathbf{N}(\%)$ & $\mathbf{N}(\%)$ & $\mathbf{N}(\%)$ & $\mathbf{N}(\%)$ & $\mathbf{N}(\%)$ & N (\%) & $\mathbf{N}(\%)$ \\
\hline $20-24$ & $164(18.0)$ & $151(17.2)$ & $49(18.2)$ & $32(11.9)$ & $7(14.0)$ & $7(21.2)$ & $1(4.7)$ & $16(16.3)$ & $427(17.1)$ \\
\hline $25-29$ & $155(17.0)$ & $174(19.9)$ & $51(19.1)$ & $42(17.2)$ & $10(20.0)$ & $9(27.2)$ & $4(19.0)$ & $16(16.3)$ & $461(18.4)$ \\
\hline $30-34$ & $188(20.6)$ & $179(20.5)$ & $41(14.5)$ & $39(15.6)$ & $9(18.0)$ & $5(15.1)$ & $8(38.0)$ & $17(17.3)$ & $486(19.4)$ \\
\hline $35-39$ & $168(18.4)$ & $144(16.5)$ & $46(16.8)$ & $43(17.8)$ & $11(22.0)$ & $7(21.2)$ & - & $21(21.4)$ & $440(17.5)$ \\
\hline $45-49$ & $74(8.1)$ & $66(7.5)$ & $43(15.4)$ & $50(21.6)$ & $4(8.0)$ & $1(3.0)$ & $5(23.8)$ & $13(13.3)$ & $256(10.3)$ \\
\hline Total & $910(100)$ & $873(100)$ & $274(100)$ & $245(100)$ & $50(100)$ & $33(100)$ & $21(100)$ & $98(100)$ & $2504(100)$ \\
\hline
\end{tabular}

Table 2. shows that $71.2 \%$ of respondents who already have children vaccinated them fully whereas $2.0 \%$ from urban areas and $1.3 \%$ from rural areas explicitly reject vaccination. $25.4 \%$ of respondents say they partially vaccinated children or they don't know the vaccination status of their children. They are a part of those ,indecisive“ who are doubtful of vaccination necessity. The limitations of this study are related to the inability of checking the given answers.

Analysing the question "Are you going to vaccinate your children?", respondents who don't have children mostly think that children should be vaccinated (Table 3 ).

Table 3. Are you going to vaccinate your children?

\begin{tabular}{|c|c|c|c|c|c|c|c|c|c|}
\hline \multirow{3}{*}{ Age } & \multicolumn{2}{|l|}{ Fully } & \multicolumn{2}{|c|}{ Additional vaccination } & \multicolumn{2}{|l|}{ Selectively } & \multicolumn{2}{|c|}{ No intention } & \multirow{2}{*}{ Total } \\
\hline & $\mathbf{U}$ & $\mathbf{R}$ & $\mathbf{U}$ & $\mathbf{R}$ & $\mathbf{U}$ & $\mathbf{R}$ & $\mathbf{U}$ & $\mathbf{R}$ & \\
\hline & $\%$ & $\%$ & $\%$ & $\%$ & $\%$ & $\%$ & $\%$ & $\%$ & $\%$ \\
\hline $20-24$ & $121(29.5)$ & $139(26.1)$ & $6(6.1)$ & $13(17.8)$ & $17(14.9)$ & $15(12.8)$ & $12(14.0)$ & $4(6.1)$ & $327(21.9)$ \\
\hline $25-29$ & $101(24.6)$ & $141(26.4)$ & $19(19.3)$ & $11(15.0)$ & $21(18.4)$ & $26(22.2)$ & $13(15.1)$ & $19(29.2)$ & $351(23.4)$ \\
\hline $30-34$ & $99(24.1)$ & $137(25.7)$ & $21(21.4)$ & $17(23.2)$ & $36(31.6)$ & $30(25.6)$ & $12(14.0)$ & $21(32.3)$ & $373(24.9)$ \\
\hline $35-39$ & $45(11.0)$ & $63(11.8)$ & $22(22.4)$ & $14(19.1)$ & $15(13.1)$ & $18(15.3)$ & $21(24.4)$ & $7(10.7)$ & $205(13.7)$ \\
\hline $45-49$ & $16(3.9)$ & $19(3.6)$ & $13(13.2)$ & $8(11.0)$ & $13(11.4)$ & $16(13.7)$ & $13(15.1)$ & $5(7.6)$ & 103 (6.9) \\
\hline Total & 410 & 533 & 98 & 73 & 114 & 117 & 86 & 65 & $1496(100.0)$ \\
\hline
\end{tabular}

Respondents without children mostly plan to vaccinate their children fully $(63.0 \%)$. Chi-square ( 18.42 ; df (3), $\mathrm{p}=$ 0.010 ) indicates that there is a statistically significant distinction between respondents according to their place of living. However, $10.1 \%$ of respondents without children say that they have no intention of vaccinating their children, while $15.4 \%$ of them would do it selectively, with certain vaccine.

Respondents were given 8 potential reasons for vaccinating or not vaccinating their children (Table 4). 
Table 4. Reasons for not vaccinating children.

\begin{tabular}{llll}
\hline & \multicolumn{2}{l}{ Place of living } & Total \\
\cline { 2 - 4 } Reasons for not vaccinating your child/children: & urban & N (\%) & N (\%) \\
\cline { 2 - 4 } & $\mathbf{N}(\%)$ & $396(43.6)$ & $712(39.8)$ \\
\hline Paediatrician recommendation on delayed vaccination & $316(35.2)$ & $68(7.4)$ & $100(5.5)$ \\
Determined permanent contraindications & $32(3.6)$ & $136(15.0)$ & $312(17.3)$ \\
Personal decision & $176(19.6)$ & $44(4.8)$ & $116(6.4)$ \\
Different working hours of medical institutions & $72(8.0)$ & $72(7.9)$ & $100(5.5)$ \\
Lack of vaccines & $28(3.1)$ & $40(4.4)$ & $116(6.4)$ \\
My friends/colleagues have made the same decision & $76(8.4)$ & $68(7.4)$ & $104(5.7)$ \\
A child gets sick after getting vaccine & $36(4.0)$ & $84(9.2)$ & $244(13.5)$ \\
Competence mistrust of medical staff & $160(17.8)$ & $908(100.0)$ & $1804(100.0)$ \\
Total & $896(100.0)$ & & \\
\hline
\end{tabular}

Chi square indicates that there are significant statistical differences between respondents from urban and those from rural areas when it comes to this question (97.06; df (7) i p < $0.001)$. There were only $5.5 \%$ cases of not vaccinated children as a result of determined permanent contraindications.

For the vaccine safety, respondents were to decide on the scale from 1 to 5, from "uncertain" to "absolutely certain" (Figure 1).

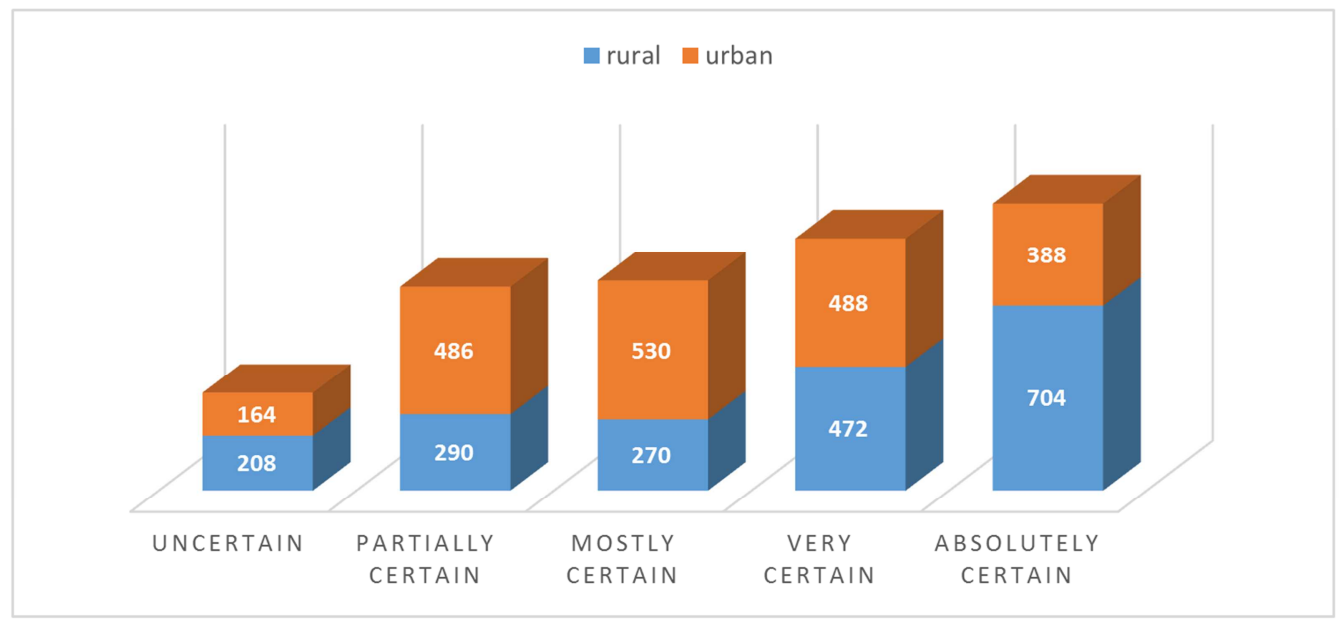

Figure 1. Opinion on the scheduled vaccine safety.

Chi-square indicates that there is a significant statistical difference according to the respondents' place of living (233.25; df (4) $\mathrm{p}<0.001) .60 .5 \%$ of respondents from rural areas are absolutely or very certain about vaccine safety while $42.6 \%$ of respondents from urban areas have the same answer.
Further questions required some information about the sources from which respondents mostly get information about vaccination regardless of the significance of information and to what extent it affected creating attitudes to immunisation (Figure 2).

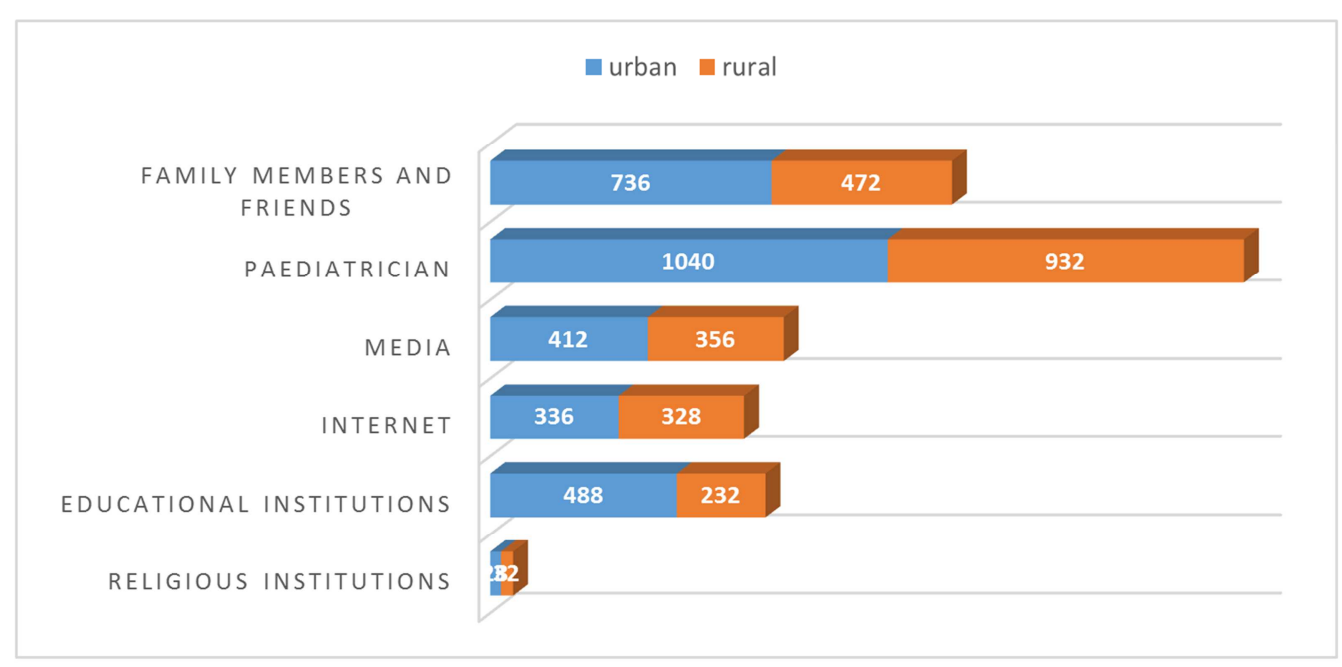

Figure 2. What is the source of information about vaccination? 
Respondents could have more than one answer to this question. Most of respondents (58.54\%) said that the source of information had been their paediatrician and members of family or friends. Chi-square (72.45 df (5), $\mathrm{p}<0.001)$ indicates that there is a significant distinction between respondents according to the source of information.

For the question "Do you think that medical workers hide the real truth about negative side effects of vaccines?" only $40.6 \%$ of respondents claim that they completely trust their doctor (Figure 3).

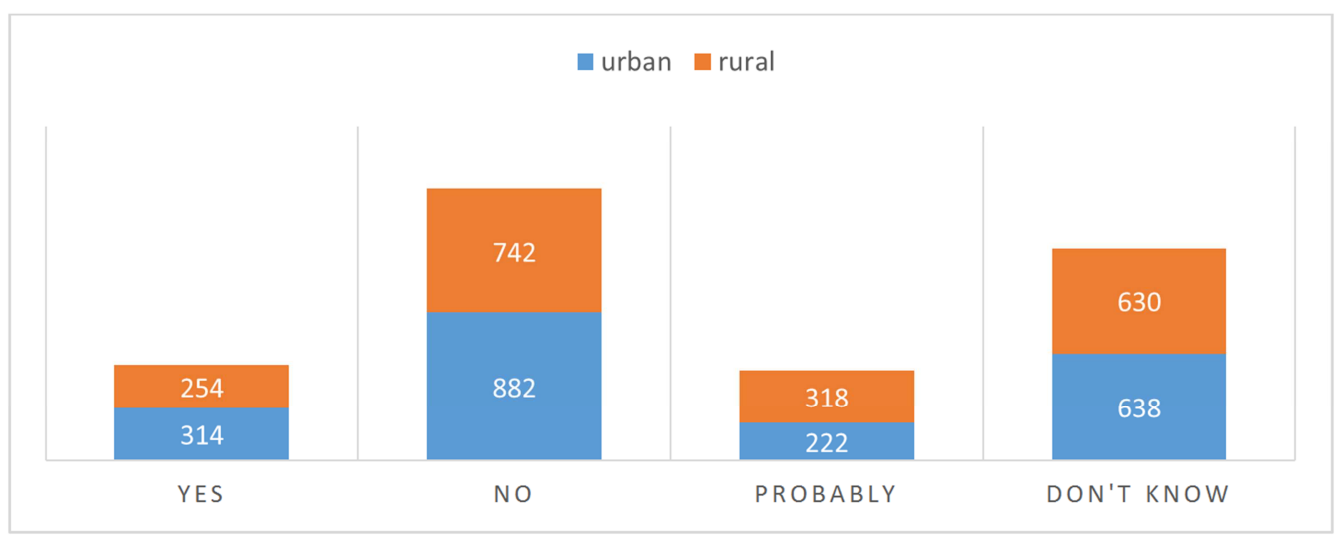

Figure 3. Results on trusting medical workers.

Test result of chi-square $(32.40 \mathrm{df}(3), \mathrm{p}=000034)$ is bigger than theoretical which indicates that there is statistically significant difference between respondents answering the question "Do you think that medical workers hide the real truth about negative side effects of vaccines?"
Next table shows the results of respondents referring to those claims which are used to check respondents' attitudes and beliefs as the most frequent dilemmas for deciding on vaccinating children (Table 5).

Table 5. Attitudes and beliefs on vaccines in this study.

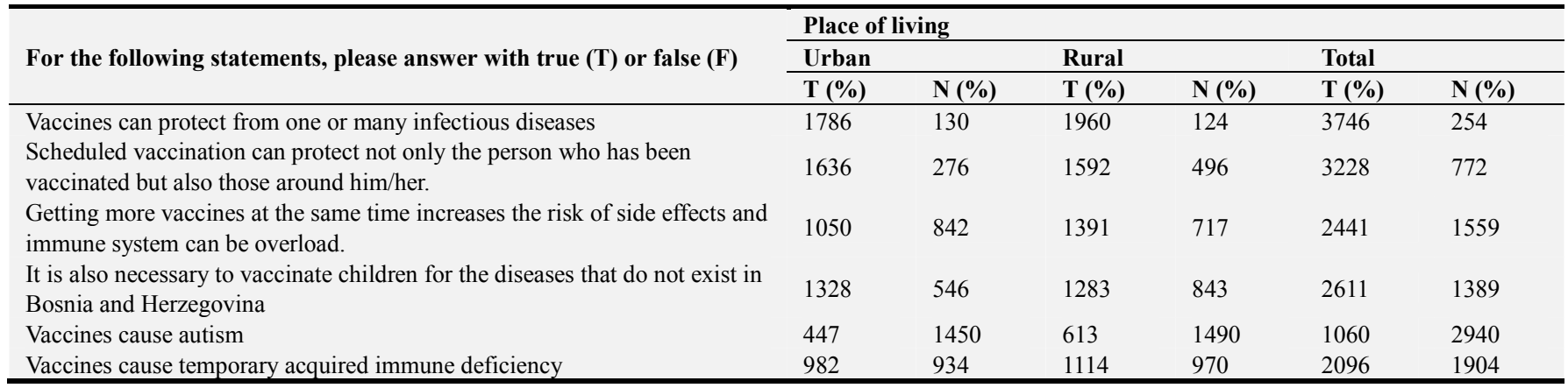

$52.4 \%$ of respondents think that vaccines cause temporary acquired immune deficiency while $26.5 \%$ think that vaccines cause autism. Also, a simple majority of respondents (61.0\%) support the claim that getting more than one vaccine at the same time increases the risk of side effects and can overload the immune system.

Most of respondents (1540 ili 38.5\%) answered that they would not like to be a part of the campaign for the vaccination promotion while $1832(45.8 \%)$ would. The rest of respondents are indecisive in this case. There is a statistical difference in the attitude about the participation in the campaign according to their place of living (chi-square 31.54 , df (2); $\mathrm{p}=.000007)$. Mostly respondents from urban areas are ready to take part in the campaign. In addition to the abovementioned, respondents also discussed the real need for such campaign realisation (Table 6).

Table 6. Respondents' opinion on the need for organising campaign for the vaccination promotion.

\begin{tabular}{llllll}
\hline \multirow{2}{*}{ Place of living } & \multicolumn{2}{l}{ Respondents' opinion } & & Hidden conspiracy and alliance beween \\
\cline { 2 - 6 } & Real need & $\begin{array}{l}\text { Campaigns are } \\
\text { past legacy }\end{array}$ & $\begin{array}{l}\text { Campaigns come as a result of the } \\
\text { pharmaceutical companies impact }\end{array}$ & $\begin{array}{l}\text { Total } \\
\text { some international organisations }\end{array}$ \\
\hline Rural & 1159 & 153 & 166 & 466 \\
urban & 1338 & 129 & 157 & 432 & 894 \\
ukupno & 2497 & 282 & 323 & 4056 \\
\hline
\end{tabular}

Test result of chi-square ( $31.60 \mathrm{df}(3) \mathrm{p}<0.001)$ is bigger than theoretical value which implies that there is a distinctive opinion on the campaign needs according to the respondents' place of living. This intervention is supported by $62.42 \%$ of 
respondents while those who are against campaigns are mostly those who think that campaigns come as a result of the impact of pharmaceutical companies $(22.45 \%)$.

\section{Discussion}

The effects of the immunisation program are shown if the coverage of the target group is $95 \%$. Our research shows that only $71.2 \%$ of respondents fully vaccinated their children. For the last two decades, more and more parents form industrialised world have decided not to vaccinate their children. Many of these had found some information about vaccines from many different sources earlier, such as the media or websites, where the content comes from antivaccination movement [9]. Such movements usually use issues such as vaccine safety doubts and lack of monitoring of post immunisation consequences known as adverse events following immunisation (AEFI) [10].

Although, vaccination acceptance is on a high level, fear of getting vaccine has increased dramatically in recent years. In some communities, this fear led to significantly high rate of vaccination hesitancy, especially for those vaccines that are related to diseases and deaths that could have been prevented by vaccination, and high costs for health care and society $[11,12]$.

Exact vaccine acceptance measuring is important, especially in these conditions when disinformation can increase public concern and politicize vaccination policy. Certain authors have tried to develop an instrument for vaccine acceptance measurement among general public [13].

Our research has shown that parents mostly get information about vaccination from medical workers, in the first place paediatricians $(36.6 \%)$. Parents usually want to hear that paediatricians and family doctors also vaccinate their own children and they want to talk about their experience. Medical professionals are generally for vaccination. However, some of them may be a part of those who are indecisive when it comes to vaccines. Results of the study done in Quebec, Canada have shown that significant number of respondents, out of 540 medical workers participating in the study, is concerned about vaccination. Indeed, more than $1 / 3$ agreed that children get too many vaccines $(37 \%)$ and that a good lifestyle can eliminate vaccination necessity (36\%) [14].

Many current and future health care professionals (HCP) are unready or reluctant to initiate a conversation about the vaccine with reluctant patients [15].

The research results, which aimed to identify medical service and medical literature as a primary source of information about vaccines, indicate that respondents pointed out inadequate communication about available vaccines. Comments on the level of confidence and trust in health care system and government are different depending on location, where the highest level of confidence people have shown in Botsvana, while lower level can be seen in Greece [16].

Our research also suggests that a significant level of mistrust towards medical workers shoul be noted. Only
$40.6 \%$ of respondents completely trust their doctor. Furthermore, a strong impact of family members and friends can be observed. Respondents $(22.4 \%)$ say that they rely on the information that they get from family members or friends. Personal experience and mutual trust are the key factors for sharing information about vaccination importance. It is necessary to encourage parents who have already vaccinated their children to talk about their decision and to become members of an online community with positive stories about immunisation [17, 18]. It is necessary to use various techniques to further strengthen this decision, such as addressing pain during vaccination to prevent fear of needle, indecision of vaccination and avoidance of health care [19].

Besides this, those stories about people who got diseases that could have been prevented by vaccines should be a part of the public discourse again. [20]. Information like this should target the population of parents who have some doubts on the vaccination necessity.

Our research has shown that more than $25 \%$ of parents and $16 \%$ of future parents have make a group of those indecisive respondents.

Hesitation - hesitancy - is a new word in medical literature and discourse on decision making and determinants for accepting vaccination. Continuum has been recognized between the scope of accepting and rejecting vaccines and former characteristics of individuals and groups known as anti-vaccines or pro-vaccines have been depolarisated by this new notion [21].

Reasons for indecision or hesitancy vary in different countries and are context specific, which implies that there is a necessity for strengthening capacities of national programs for identification of locally relevant factors and development of adjusted strategies for solutions. [22, 23].

A literature review and meta-analysis indicate that there is no clear evidence that would recommend any specific intervention to deal with the problem of hesitancy [24-27]. Globally, most of those interventions analysed in this study are primarily informing and education about vaccine.

Short written educational interventions (eg. brochure, leaflet) are one of the most promising interventions included in the review. Although some studies show statistically significant improvement of accepting vaccines, results were inconsistent and mostly there were low or moderate quality evidence. None of the reviews included recommendations for specific kind of informative or educational interventions as an effective strategy for increasing the vaccination acceptance or decreasing hesitancy [14, 24].

The study conducted in four European countries points out the result that doctors are responsible for indecisive patients and that they should respond to this problem [28].

Regardless of the thesis that the internet and social networks have crucial impact on the respondents' opinion about accepting vaccination, our research has shown that social networks and the internet are in the fifth place on the sources of information scale (16.6\%), after medical workers, family members, media and educational institutions. There is no significant distinction between respondents when it comes 
to the internet impact according to the place of living.

Many authors reviewed interventions that use new media (internet and social media) for the vaccine promotion and to increase vaccine coverage. Some of them concluded that messaging, surfing websites about vaccine campaigns, using web-based portals and computerised reminders can increase vaccinating, while there was lack of evidence to determine the efficacy of using social networks, e-mails and smart phone applications [29].

However, it is important to point out that anti-vaccine information dominates on the Internet. Many anti-vaccination campaign websites post pictures and stories in order to convince people that they should not get vaccinated. The research published by Journal of the American Medical Association stressed out that $32 \%$ of anti-vaccine websites posted various pictures of children and adults with complications and diseases due to vaccination, and that $23 \%$ of websites posted stories of parents who vaccinated their children and who sufferd complications due to it [30].

Internet allows information diffusion, often using "click bait" headlines, presenting issues without scientific facts. Studies that analyse the websites or social networks related to vaccination show that the quality of the given information is very variable, with big amount of false information [31].

This has led to the environment in which anti-vaccine activists can efficiently spread their message [32].

Results of this research imply that vaccination safety is different in urban and rural population. Only $18.8 \%$ of urban population said that they completely trust vaccines, whereas in rural area that number is $36.2 \%$. Feeling of vaccine safety and trust is very negative in The European region, where seven countries out of ten have the lowest level of trust including $41 \%$ of respondents in France and $36 \%$ in Bosnia and Herzegovina who say that vaccines are not safe (compared to global average of 13\%) [33].

$61 \%$ of respondents agree that getting more than one vaccine at the same time can lead to some negative side effects and overload immune system.

One of the reasons to reject vaccines is lack of trust in adequate documentation and only a few communicational startegies explicitly tried to enhance this trust. The results of the study, which tested the possibility of using data from Vaccine Adverse Event Reporting System (VAERS) to increase trust, imply that if the adverse event is studied adequately and if potential damages are open to public, the vaccination perception is improved [34].

Vaccination pressure can be counterproductive. Listening and speaking can support personal decision-making and can better inform public health community about questions and problems related to vaccine hesitancy [35]. Targeted training can overcome rejection of the vaccine and can identify differences in parents' motives for refusing vaccination and indicate the existence of different places for potential provaccination interventions [36].

Key step in a successful communication of public health is identifying those who are very sensitive in finding and using unreliable and deceiving information. So, it is inevitable for the public health websites to be easily available, used and attractive with its presentations and posts and to provide information, support and advice for those who surf the website [37].

\section{Conclusion}

The importance of fear understanding of different groups of individuals who disagree on scheduled vaccinating is significant for creating strategies for increasing vaccination coverage. Considering the lack of information about public health intervention effects, it is inevitable for the public health to keep searching for effective strategies that could regain vaccination trust.

Results imply that there is a necessity to ensure that medical professionals, and those who are participating in immunisation programs, have become better informed about the benefits of vaccines and that they can identify wider impacts on vaccination hesitancy.

Vaccination hesitancy is an individual behaviour, but it is also the result of wider social impacts and it should always be analysed in a historical, political, social and cultural context in which vaccination takes place.

It can be concluded that personal experience, public system efficacy, trust in medical professionals, vaccine safety and communication in public health community are crucial for parents making decisions on vaccinating their children.

\section{References}

[1] Emrah Altindis. Antibacterial vaccine research in 21st century: from inoculation to genomics approaches. Current Topics in Medicinal Chemistry. Vol. 13, No. 20, 2013, pp. 2638-2646.

[2] Michael S. Gold, Jane Gidudu, Mich Erlewyn-Lajeunesse, Barbara Law. Brighton Collaboration Working Group on Anaphylaxis. Can the Brighton Collaboration case definitions be used to improve the quality of Adverse Event Following Immunization (AEFI) reporting? Vaccine. Vol. 28, No. 28, 2010, pp. 4487-4498.

[3] David Ropeik. How society should respond to the risk of vaccine rejection. Human Vaccines \& Immunotherapeutics. Vol. 9, No. 8, 2013, pp. 1815-1818.

[4] Robert M Wolfe, Lisa K Sharp. Anti-vaccinationistis past and present. British Medical Journal. Vol. 325. No. 7361, 2002, pp. 430-432.

[5] Jeffrey P. Baker. The pertussis vaccine controversy in Great Britain. Vaccine. Vol. 21. No. 25-26, 2003, pp. 4003-4010.

[6] Fiona Godlee, Jane Smith, Harvey Marcovitch. Wakefield's article linking MMR vaccine and autism was fraudulent. British Medical Journal. Vol. 342, No. 7452, 2011, pp. 6467.

[7] Laura Eggertson. Lancet retracts 12-year-old article linking autism to MMR vaccines. The Canadian Medical Association Journal. Vol. 182, No. 4, 2010, pp. 199-200. 
[8] Qudsia Anjum, Aamir Omair, Bazmi Inam, Yousuf Ahmed, Yaseen Usman, Shazia Shaikh. Improving vaccination status of children under five through health education. Journal of the Pakistan Medical Association. Vol. 54, No. 12, 2004, pp. 610613.

[9] Silvio Tafuri, Maria Serena Gallone, Maria Giovanna Cappelli, Domenico Martinelli, Rosa R. P. Prato, Cinzia Annatea Germinario. Addressing the anti-vaccination movement and the role of HCWs. Vaccine. Vol. 32, No. 38, 2014, pp. 4860-4865.

[10] Silvio Tafuri, Maria Serena Gallone, Giulia Calabrese, Cinzia Germinario. Adverse events following immunization: is this time for the use of WHO causality assessment? Expert Review of Vaccines. Vol. 14, No. 5, 2015, pp. 625-627.

[11] David Ropeik. How society should respond to the risk of vaccine rejection. Human Vaccines \& Immunotherapeutics. Vol. 9, No. 8, 2013, pp. 1815-1818.

[12] Angela Bechini, Sara Boccalini, Alessandra Ninci, Patrizio Zanobini, Gino Sartor, Guglielmo Bonaccorsi, Maddalena Grazzini, Paolo Bonanni. Childhood Vaccination Coverage in Europe: Impact of different Public Health Policies. Expert Review of Vaccines. 2019.

[13] Dilshani Sarathchandraa, Mark C. Navinb, Mark A. Largentc, Aaron M. McCright. A survey instrument for measuring vaccine acceptance. Preventive Medicine. Vol. 109, 2018, pp. $1-7$.

[14] Eve Dubé, Caroline Laberge, Maryse Guay, Paul Bramadat, Real Roy, Julie Bettinger. Vaccine hesitancy: an overview. Human Vaccines \& Immunotherapeutics. Vol. 9, No. 8, 2013, pp. 1763-1773.

[15] Lauren L. Dybsand, Kylie J. Hall, Paul J. Carson. Immunization attitudes, opinions, and knowledge of healthcare professional students at two Midwestern universities in the United States. BMC Medical Education. Vol. 19, No. 1, 2019, pp. 242-251.

[16] Lori K. Handy, Stefania Maroudi, Maura Powell, Bakanuki Nfila, Charlotte Moser, Ingrid Japa, Ndibo Monyatsi, Elena Tzortzi, Ismini Kouzeli, Anthony Luberti, Maria Theodoridou, Paul Offit, Andrew Steenhoff, Judy A. Shea, Kristen A. Feemster. The impact of access to immunization information on vaccine acceptance in three countries. Public Library of Science One. Vol. 12, No. 8, 2017, pp. 3-19.

[17] Ashley Shelby, Karen Ernst. Story and science: how providers and parents can utilize storytelling to combat anti-vaccine misinformation. Human Vaccines \& Immunotherapeutics. Vol. 9, No. 8, 2013, pp. 1795-1801.

[18] Regina Célia de Menezes Succi. Vaccine refusal - what we need to know. Jornal de Pediatria (Rio J). Vol. 94, No. 6, 2018, pp. 574-581.

[19] Terri MacDougall, Shawna Cunningham, Leeann Whitney, Monakshi Sawhney. Improving pediatric experience of pain during vaccinations: a quality improvement project. International Journal of Health Care Quality Assurance. Vol. 32, No. 6, 2019, pp. 1034-1040.

[20] Julie Leaskab, Simon Chapmanb, Penelope Hawec, Margaret Burgess. What maintains parental support for vaccination when challenged by anti-vaccination messages? A qualitative study. Vaccine. Vol. 24, No. 49-50, 2006, pp. 7238-7245.
[21] Heidi J. Larson, Caitlin Jarrett, Elisabeth Eckersberger, David M. D. Smith, Pauline Paterson. Understanding vaccine hesitancy around vaccines and vaccination from a global perspective: a systematic review of published literature, 20072012. Vaccine. Vol. 32, No. 19, 2014, pp. 2150-2159.

[22] Eve Dubéabc, Dominique Gagnona, Emily Nickelsd, Stanley Jeramd, Melanie Schusterd. Mapping vaccine hesitancy-country-specific characteristics of a global phenomenon. Vaccine. Vol. 32, No. 49, 2014, pp. 6649-6654.

[23] Eve Dubé, Dominique Gagnon, Manale Ouakki, Julie A. Bettinger, Holly O. Witteman, Shannon Mac Donald, William Fisher, Vineet Saini, Devon Greyson; Canadian Immunization Research Network. Measuring vaccine acceptance among Canadian parents: A survey of the Canadian Immunization Research Network. Vaccine. Vol. 36, No. 4, 2018, pp. 545-552.

[24] Eve Dubéa, Dominique Gagnona, Noni E. MacDonaldb, the SAGE Working Group on Vaccine Hesitancy. Strategies intended to address vaccine hesitancy: Review of published reviews. Vaccine. Vol. 33, No. 34, 2015, pp. 4191-4203.

[25] Margarida Arede, Maria Bravo-Araya, Émilie Bouchard, Gurlal Singh Gill, Valerie Plajer, Adiba Shehraj, Yassir Adam Shuaib. Combating Vaccine Hesitancy: Teaching the Next Generation to Navigate Through the Post Truth Era. Frontiers in Public Health. Vol. 14, No. 6, 2019, pp. 381-387.

[26] Jeroen Luyten, Luk Bruyneel, Albert Janvan Hoek. Assessing vaccine hesitancy in the UK population using a generalized vaccine hesitancy survey instrument. Vaccine. Vol. 37, No. 18, 2019, pp. 2494-2501.

[27] Katharina Kieslich. Addressing vaccination hesitancy in Europe: a case study instate-society relations. European Journal of Public Health. Vol. 28, No. 3, 2018, pp. 30-33.

[28] Emilie Karafillakisa, Irina Dincab, Franklin Apfelc, Sabrina Cecconic, Andrea Würzb, Judit Takacsb, Jonathan Sukb, Lucia Pastore Celentanob, Piotr Kramarzb, Heidi J. Larson. Vaccine hesitancy among healthcare workers in Europe: A qualitative study. Vaccine. Vol. 34, No. 41, 2016, pp. 5013-5020.

[29] Anna Odone, Antonio Ferrari, Francesca Spagnoli, Sara Visciarelli, Abigail Shefer, Cesira Pasquarella, Carlo Signorelli. Effectiveness of interventions that apply new media to improve vaccine uptake and vaccine coverage. Human vaccines \& immunotherapeutics. Vol. 11, No. 1, 2015, pp. $72-82$.

[30] Robert M. Wolfe, Lisa K. Sharp, Martin Stephen Lipsky. Content and Design Attributes of Antivaccination Web Sites. Journal of the American Medical Association. 287 (24): 2002, pp. 3245-3248.

[31] Holly O. Wittemanab, Brian J. Zikmund-Fisher. The defining characteristics of Web 2.0 and their potential influence in the online vaccination debate. Vaccine. Vol. 30, No. 25, 2012, pp. 3734-3740.

[32] Anna Kata. Anti-vaccine activists, Web 2.0, and the postmodern paradigm - an overview of tactics and tropes used online by the anti-vaccination movement. Vaccine. Vol. 30, No. 25, 2012, pp. 3778-3789.

[33] Heidi J. Larson, Alexandre de Figueiredo, Zhao Xiahong, William S. Schulz, Pierre Verger, Iain G. Johnston, Alex R. Cook, Nick S. Jones. The State of Vaccine Confidence 2016: Global Insights Through a 67-Country Survey. EBioMedicine. Vol. 12, 2016, pp. 295-301. 
[34] Laura D. Scherera, Victoria A. Shafferab, Niraj Patela, Brian J. Zikmund-Fisherc. Can the vaccine adverse event reporting system be used to increase vaccine acceptance and trust? Vaccine. Vol. 34, No. 21, pp. 2424-2429.

[35] Heidi J Larson. Negotiating vaccine acceptance in an era of reluctance. Human vaccines \& immunotherapeutics. Vol. 9, No. 8, 2013, pp. 1779-1781.

[36] Mark C. Navin, Jason Adam Wasserman, Miriam Ahmad, Shane Bies. Vaccine Education, Reasons for Refusal, and
Vaccination Behavior. American Journal of Preventive Medicine. Vol. 56, No. 3, 2019, pp. 359-367.

[37] Cornelia Betscha, Noel T. Brewerb, Pauline Brocardc, Patrick Daviesd, Wolfgang Gaissmaiere, Niels Haasea, Julie Leaskf, Frank Renkewitza, Britta Rennerg, Valerie F. Reynah, Constanze Rossmanni, Katharina Sachsej, Alexander Schachingerk, Michael Siegristl, Marybelle Stryk. Opportunities and challenges of Web 2.0 for vaccination decisions. Vaccine. Vol. 30, No. 25, 2012, pp. 3727-3733. 